\title{
Novel genetic approaches to behavior in Drosophila
}

\author{
Fernando Martín (D) and Esther Alcorta \\ Department of Functional Biology (Genetics), University of Oviedo, Oviedo, Spain
}

\begin{abstract}
The study of behavior requires manipulation of the controlling neural circuits. The fruit fly, Drosophila melanogaster, is an ideal model for studying behavior because of its relatively small brain and the numerous sophisticated genetic tools that have been developed for this animal. Relatively recent technical advances allow the manipulation of a small subset of neurons with temporal resolution in flies while they are subject to behavior assays. This review briefly describes the most important genetic techniques, reagents, and approaches that are available to study and manipulate the neural circuits involved in Drosophila behavior. We also describe some examples of these genetic tools in the study of the olfactory receptor system.
\end{abstract}

ARTICLE HISTORY

Received 27 July 2017

Accepted 19 October 2017

\section{KEYWORDS}

Behavior; Drosophila; molecular tools; neuronal circuits; binary expression systems; Gal4-UAS; LexALexAop; QF-QUAS

\section{Introduction}

Many animals exhibit similar behaviors in response to specific sensory signals. For example Drosophila may exhibit similar emotional behaviors to those of mammals (Iliadi, 2009). Genetically defined neural circuits likely control innate behaviors because genetically identical individuals of the same species have similar behavior responses (Simpson, 2009). And neural circuits of adaptive behaviors are able to evolve via modification of the synaptic connections between neurons (Simpson, 2009). For several years, anatomical and electrophysiological studies have been used to map neural circuits in both invertebrates and vertebrates and even to understand the full connectivity circuits of the nervous system of C. elegans (Bargmann \& Marder, 2013). In Drosophila, for example, the complete map of conexions in a center of learning and memory in the larvae was described recently (Eichler et al., 2017). However, a behavior depends not only on the contacts between the neurons in the circuit (the connectome) but also on the mode of signaling of each neuron, the magnitude of the connections between neurons and other physiological and environmental factors that can alter neural circuit dynamics (Bargmann \& Marder, 2013).

The greatest difficulties in the study of behavior is the precise mapping of circuits, determining the roles of each cell and its connections in the circuit and coupling all of these factors with behavioral readouts. Invertebrates are good models to investigate complex brain functions, such as behavior, because of their relatively small nervous systems. However, the functional manipulation of neurons is required to decipher behavior, even in models with a reduced number of neurons. These neurons must be switched on and off while monitoring the activity of the circuit and the behavior of the animal. For example, optogenetics may be used to modify a behavior when light sensitive channels are expressed in a neural circuit. Therefore, the targeted expression of effectors that may modify neuronal activity in a small subsets of neurons in a circuit, as with optogenetics, would allow the functional mapping of the circuit (White \& Peabody, 2009). Many molecular and genetic tools that allow this targeted expression and several effectors used for the functional manipulation of neural circuits have been developed in the fruit fly Drosophila melanogaster and these tools are discussed in this review.

\section{Drosophila as a model for behavior}

Since Morgan's first experiments, the fruit fly has served as a model in various biological disciplines, and the sequencing of the Drosophila genome has shown that many fly and human genes are homologous (Rubin et al., 2000). Flies are inexpensive to maintain, have short generation times and produce hundreds of descendants. Furthermore, there are fewer ethical concerns associated with the studies in Drosophila than with those using mammalian species.

The fruit fly's nervous system, with 100,000 neurons in its brain (Ito, Masuda, Shinomiya, Endo, \& Ito, 2013), has an intermediate complexity between C. elegans and mammals. They have many sensory organs to sense sounds, images, smells, tastes, and touches (see reviews: Behnia \& Desplan, 2015; Herrero, 2012; Kamikouchi, 2013; Lumpkin, Marshall, \& Nelson, 2010; Martin, Boto, Gomez-Diaz, \& Alcorta, 2013). These senses gather information from the external world that the nervous system translates into behavioral responses, thus allowing the survival and propagation of the species. These behaviors have been studied in Drosophila

CONTACT Fernando Martín martinljose@uniovi.es $=$ Department of Functional Biology (Genetics), Faculty of Medicine, University of Oviedo, Calle Julian Claveria, 6, Oviedo 33006, Spain

(C) 2017 Informa UK Limited, trading as Taylor \& Francis Group 
using a single-gene mutant approach since the studies performed in Seymour Benzer's lab in the mid-1960s (Benzer, 1973). They started studying the genes involved in circadian rhythms, courtship, and learning and memory behaviors (see review Sokolowski, 2001), and many other behaviors have been studied using the same approach, ranging from simple behaviors, such as olfaction and taste preference (Vosshall \& Stocker, 2007), to more complex behaviors, such as group behaviors (Ramdya, Schneider, \& Levine, 2017). This approach has also been used as a model for human conditions, such as alcoholism (Park, Ghezzi, Wijesekera, \& Atkinson, 2017) and neurodegenerative diseases (McGurk, Berson, \& Bonini, 2015).

\section{Basic genetic tools in Drosophila}

Many sophisticated genetic tools have been developed to manipulate genes, cells, and ultimately behavior of the fruit fly. In Drosophila, the natural transposable P-element was used for germ-line transformation to introduce DNA into the genome (Rubin \& Spradling 1982; Spradling \& Rubin 1982). This technique was used to generate a vast collection of transgenic flies that are used to produce mutations in specific genes, deletions, and duplications of larger genome sections, homologous recombination and gene replacements, gene miss-expression, enhancer-trap, etc. (for review see Ryder \& Russell, 2003). These transgenic fly lines are available from individual labs and stock collections of research institutes, as the Janelia Farm that used thousands of these lines to study the connectome of Drosophila brain (see, e.g., Takemura et al., 2015). And there are also public stock centers devoted to maintain and provide fly lines, such as the Bloomington Drosophila Stock Center (Bloomington, IN), the Kyoto Stock Center (Kyoto, Japan) and the Vienna Drosophila Resource Center (VDRC) (Vienna, Austria). These transgenic flies include enhancer-trap lines that are used to produce 'tissue-specific' expression of reporters or drivers (Figure 1(A)). These drivers or reporters may be expressed in the same pattern as the gene whose enhancer was 'trapped', depending on the insertion site of the transposable element (Bellen et al., 1989; O'Kane \& Gehring 1987). The enhancer-trap name is also used for inserted transposable elements that carry constructs that include the enhancer and promoter or only the promoter (or regulatory upstream sequences) of a gene that controls the expression of a reporter or driver.

The most powerful variant of the enhancer-trap technique, the Gal4-UAS binary system, provides tight temporal and/or spatial control of gene expression (Brand \& Perrimon, 1993). This system is composed of two parts: a Gal4 'driver' line, in which an enhancer-trap element drives the expression of the yeast transcriptional activator GAL4 under the control of a Drosophila promoter in a specific temporal and spatial pattern; and a UAS line, in which the sequence of a gene is inserted downstream of a Gal4 upstream activation sequence (UAS) (Figure 1(B)). Both elements are incorporated into the Drosophila genome using P-element mediated transformation in different fly lines, and these two components are combined in the same fly using genetic crosses to produce the expression of the gene controlled by UAS in the cells that express Gal4 (Brand \& Perrimon, 1993). This technique has allowed the generation of thousands of stable fly strains that have P-elements inserted in unique random positions in the fly genome (for the Gal4 lines, see http://flystocks.bio.indiana.edu/Browse/ gal4/gal4_main.htm) and that, by virtue of these positions, can be used to express other genes (controlled by the UAS, see http://flystocks.bio.indiana.edu/Browse/uas/uashome.htm) in specific cells in the animal. Gal4 lines that carry the regulatory region of a gene (enhancer and promoter or promoter alone) with known expression patterns were also generated to drive GAL4 with a similar cell-specificity (Figure 1(C)). For example, the orco gene encodes for an olfactory coreceptor that is expressed in approximately $70 \%$ of odorant receptor neurons (ORN), and fragments of the orco regulatory region drive genes to these neurons in the orcoGal4 line (Ng et al., 2002).

This Gal4-UAS system is controlled via the yeast Gal4 repressor, GAL80, which binds to GAL4 and represses its activity (Johnston, 1987). Ectopic co-expression of GAL4 and GAL80 in the fly inhibits the activity of GAL4 (Lee \& Luo, 1999). The existence of a temperature-sensitive Gal80 mutant $\left(\mathrm{Gal} 80^{\mathrm{ts}}\right)$ allows the temporal control of Gal4 activity via temperature manipulation GAL4 inhibition occurs below $25^{\circ} \mathrm{C}$ and a loss of suppression occurs above $29^{\circ} \mathrm{C}$ (McGuire, Le, Osborn, Matsumoto, \& Davis, 2003) (Figure 1(C)). Another variant of the Gal4 system, GeneSwitch, also allows temporal control of gene expression by feeding flies the hormone RU486 (Osterwalder, Yoon, White, \& Keshishian, 2001; Roman, Endo, Zong, \& Davis, 2001).

Although the Gal4-UAS binary system is widely used, two additional binary systems were developed in Drosophila. The availability of these additional systems allows Drosophila biologists to simultaneously perform two gene expression manipulations in vivo. For example, the GAL4-UAS system and one of these systems may be used to examine whether two reporters were expressed in the same or different cells.

One of these systems is the LexA-LexAop system, which takes advantage of the bacterial transcriptional factor, LexA. LexA binds specifically to LexAop sequences to produce the transcription of downstream effectors (Lai \& Lee, 2006) (Figure 1(D)). The LexA DNA-binding domain (DBD) in this system may be linked to the GAL4 activation domain or the VP16 activation domain, which is a strong activation domain from the herpes simplex virus. This combination provides GAL80-repressible (GAL4 activation domain) or independent (VP16) LexA drivers. The VP16 domain is very strong, and the LexA drivers that carry it are used to produce a high level of expression (Rodrigez, del, Didiano, \& Desplan, 2011). The second system is the Q system, which uses the QF transcription factor from Neurospora. This factor binds specifically to the QUAS gene cluster-binding site to drive expression of a downstream gene (Potter \& Luo, 2011; Potter, Tasic, Russler, Liang, \& Luo, 2010). In this system the QS element represses QF function (Figure 1(E)); this inhibition could be reversed by feeding flies with quinic acid. This system may be used to study temperature sensitive behaviors where the Gal80 thermosensitive mutants cannot 
(A)
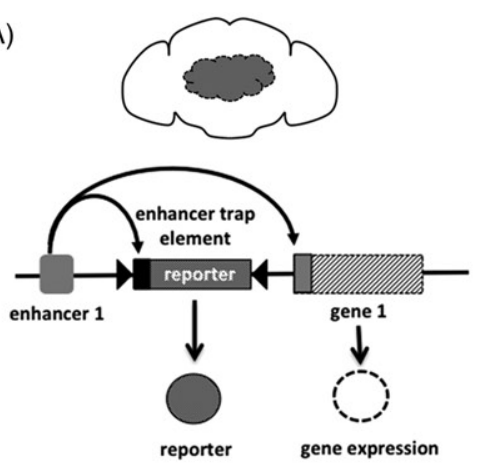

(C)
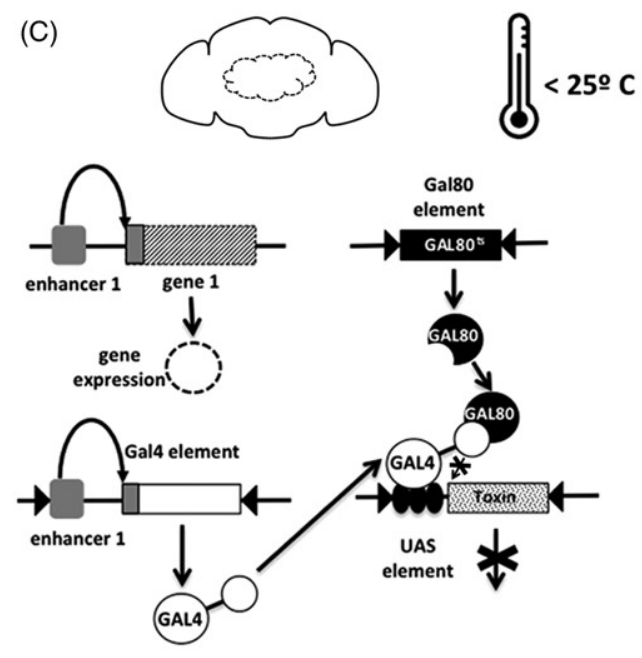

(D)
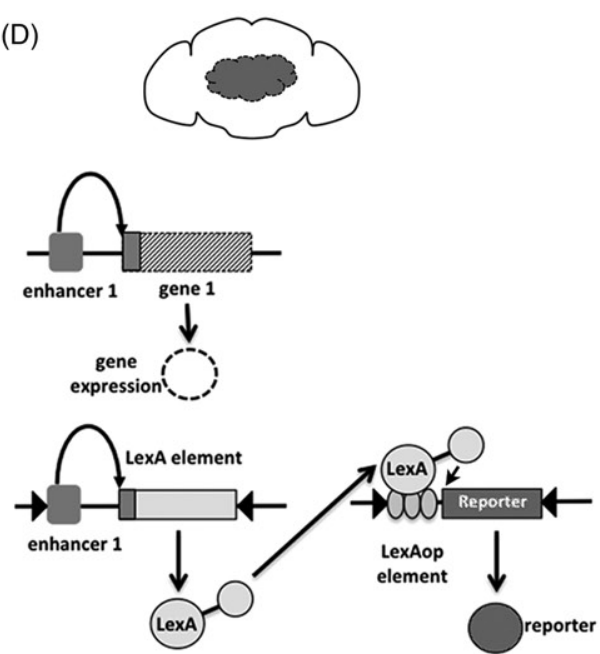

(B)
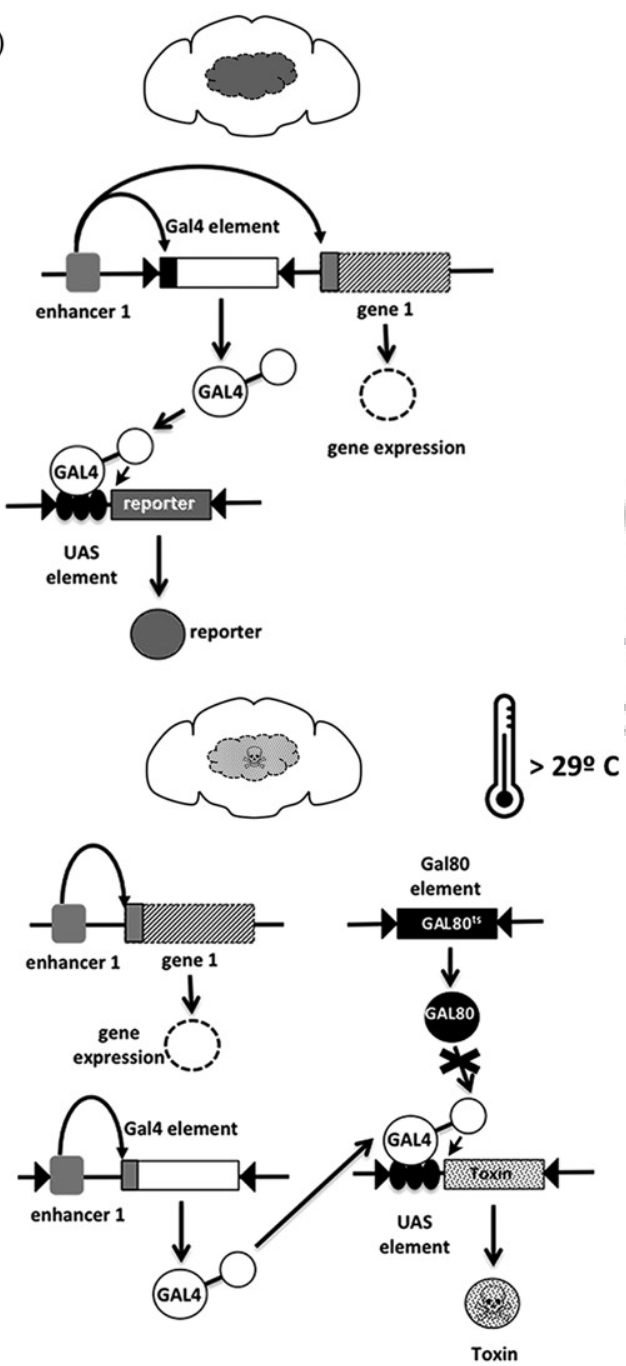

(E)
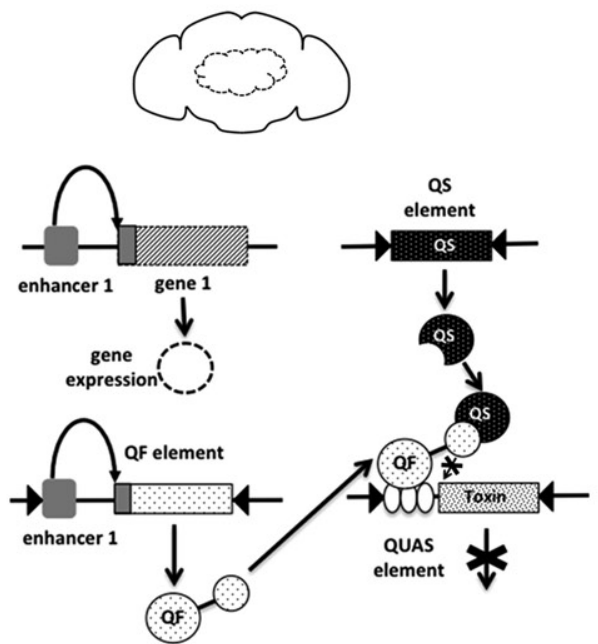

Figure 1. Basic genetic tools. A) The enhancer trap system: A modified P-element (limited by the black triangles) is inserted close to one enhancer that controls the expression of gene 1, and this produces the expression of a reporter gene carried by the P-element in the same pattern. B) The Gal4/UAS system: the P-element carries the Gal4 gene that it is expressed under the control of the nearby enhancer; the GAL4 protein is expressed in the same pattern as gene 1 and induces the expression of a reporter gene controlled by a UAS carried by another P-element inserted elsewhere in the genome. C) Control of the Gal4/UAS system by temperature: A thermosensible Gal80 mutant allele controls the expression of a toxin gene controlled by UAS in the cells that express gene 1 because the Gal4 gene is fused to the regulatory regions (enhancer and promoter) of that gene. Left, under $25^{\circ} \mathrm{C}$ the GAL80 protein codified by another P-element is attached to the GAL4 avoiding the expression of the Toxin. Right, when the temperature is raised above $29^{\circ} \mathrm{C}$, the GAL80 protein is inactivated and does not repress GAL4. Thus, the toxin is produced, killing the cells where the gene 1 is expressed. D) The LexA/LexAop binary system functions similarly to the GAL4/UAS system, but it does not have a repressor. E) The Q system functions similarly to the GAL4/UAS system, and it has a QS similar to Gal80. 
be used. Another advantages of the Q system is that it produces less basal expression because it is less leaky that the Gal4-UAS system (Rodrigez et al., 2011).

The random insertion of the transposable elements of these transgenic flies may produce position effects that strongly influence gene expression and complicate the phenotypic analysis of behaviors and other complex traits (Levis, Hazelrigg, \& Rubin, 1985). A site-specific integration system was developed in Drosophila using the site-specific integrase from phage $\varphi \mathrm{C} 31$, which mediates recombination between attB and attP sites, to avoid the random insertion of transposable elements (Groth, Fish, Nusse, \& Calos, 2004). This approach allows quantitative comparisons between different constructs inserted at the same genomic location.

\section{Strategies to refine driver expression patterns}

Many of the Gal4 driver lines used to study the nervous system have expression patterns that are too broad to be useful for fine anatomical and functional mapping of behaviors, and it is the same for the other binary systems. Furthermore, some of these lines express the driver not only in specific cells of the brain but also in other tissues, and this poses complications to the interpretation of the neural basis of behavior. To solve these problems, the fly community has developed a number of intersectional strategies to refine these expression patterns to visualize and functionally manipulate neurons using several effector genes that we will discuss later (Sivanantharajah \& Zhang, 2015).

One such strategy is the split-Gal4 system (Luan et al., 2006), where the Gal4 is separated into its two basic components: the DBD and the transcriptional activation domain $(\mathrm{AD})$, and each of these are fused to a leucine zipper motif (Figure 2(A)). These two units are expressed using two different enhancers or promoters, and in cells that co-express these two enhancers, the leucine zipper motifs bring together the $\mathrm{DBD}$ and $\mathrm{AD}$ domains to form a composite Gal4 protein that can transcribe genes placed downstream of the UAS. The disadvantages of this system are that a large collection of new enhancer-trap lines expressing the Gal4 DBD and $\mathrm{AD}$ separately needs to be established and that the modified $\mathrm{AD}$ is no longer sensitive to Gal80 inhibition.

A second split system, the Split-LexA, has been developed to overcome some of the disadvantages of the split-Gal4 (Ting et al., 2011). In this system, the LexA-DBD is expressed under UAS control in existing Gal4 lines; therefore, it could be repressed with Gal80 (Figure 2(B)). However, this system requires the production of a large number of LexA-AD constructs and is not compatible with existing UAS lines.

Another intersectional strategy is to refine Gal4 expression patterns using Gal80 repression. The Gal80 is produced through enhancer trapping or driven by specific promoters (Clyne \& Miesenbock, 2008; Keene et al., 2004), and in regions where expression of Gal4 and Gal80 overlap, the Gal80 suppresses the expression of a UAS-effector gene by
(A)
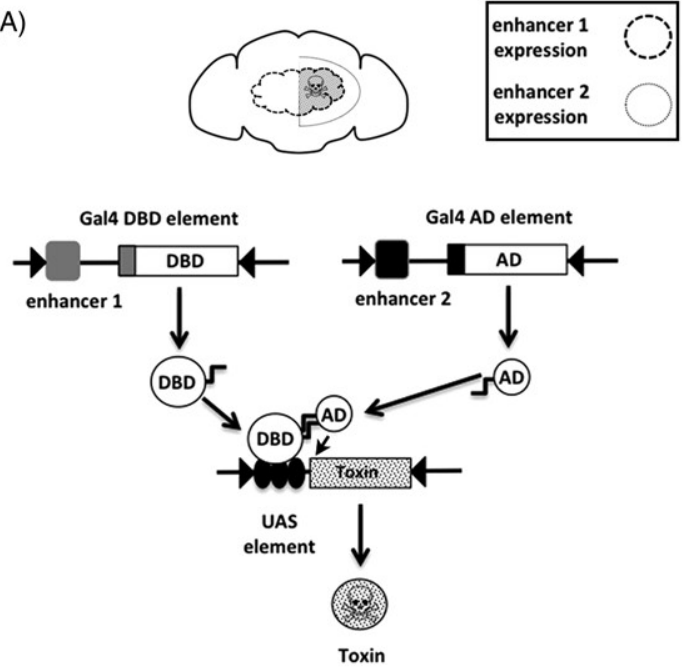

(B)
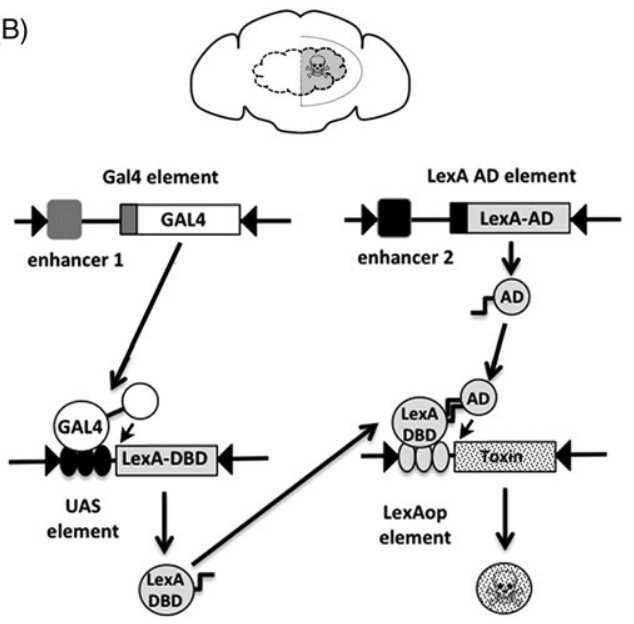

\section{-}


inhibiting the Gal4 activity (Figure 2(C)). A similar strategy could be used in the Q system using its QS repressor (Potter, Tasic, Russler, Liang, \& Luo, 2010). This technique may be limited by the ability to produce intersectional patterns small enough for accurate mapping of the minimal number of cells required for a behavior.

To further refine these patterns a second approach has been taken, where Gal80 expression is controlled by a strong promoter [e.g. the tubulin promoter (tubP)], and its expression pattern is refined using site-specific mitotic recombination using the yeast FLP-FRT system (Lee \& Luo, 2001; Gordon \& Scott, 2009). In this system, the recombinase flippase (FLP) recognizes two Flippase recognition target (FRT) sites and produces the recombination between them. If both FRT sites are in the same chromosome and in the same orientation, it would lead to the deletion of the sequence between them (Golic \& Lindquist, 1989). There are some methods that use Gal80 constructs surrounded by two FRT sites to eliminate it in the presence of FLP (Figure 3(A)). For example, this is used in the mosaic analysis with a repressible cell marker (MARCM) method that allows the visualization of cell morphology, mapping of cellular connections, and tracing of cell linages during development. In the MARCM technique, the Gal80 represses Gal4-driven expression of the green fluorescent protein (GFP) reporter and uses a FLP controlled by a heat shock promoter (hs-FLP) to delete the Gal80 repression in response to a temperature pulse at a given time during development. This process marks both the cells in which flip-out of Gal80 occurs and their descendants throughout development with GFP fluorescence (Lee \& Luo, 2001). This same approach of a Gal80 flip-out using a hs-FLP has been used to intersect Gal4 neurons in the taste circuit of flies (Gordon \& Scott, 2009).

A similar technique, but using enhancer/promoter driven FLP constructs, is called flippase-induced intersectional Gal80/Gal4 repression (FINGR) (Bohm et al., 2010) (Figure 3(B)). In this method, two FLP-dependent Gal80 constructs are used to mediate the activation or inhibition of Gal4 activity. In cells where FLP is present, with the tubP ${ }^{\mathrm{FRT}} \mathrm{Gal} 80^{\mathrm{FRT}}$ construct, the excision of Gal80 will result in the effector gene expression. However, in lines with a second construct that have a stop codon surrounded by FRT sites (tubP ${ }^{\mathrm{FRT}}$ STOP ${ }^{\mathrm{FRT}}$ Gal80), the presence of FLP produces the excision of the STOP, thus allowing the expression of Gal80 and, consequently, both the inhibition of Gal4 and the suppression of the effector gene expression. For this method, more than 1000 enhancer trap FLP lines have been produced and are used to refine the spatial and temporal resolution of existing Gal4 lines (Sivanantharajah \& Zhang, 2015).

Finally, another intersectional method is to refine UAS-effector gene patterns using FLP recombinase. When a construct of a UAS ${ }^{\mathrm{FRT}} \mathrm{STOP}{ }^{\mathrm{FRT}}$ effector is inserted into the genome, a cell-specific expression of FLP recombinase results in the removal of the STOP signal, allowing expression of the effector driven by a Gal4 (Figure 3(C)). This 'flip-In' method was first used to study courtship (Stockinger, Kvitsiani, Rotkopf, Tirian, \& Dickson, 2005), where effectors, such as temperature-sensitive paralytic shibire $\left(\operatorname{shi}^{\mathrm{ts}}\right)$ (Kitamoto, 2001) or the tetanus toxin light chain (TNT)
(Sweeney, Broadie, Keane, Niemann, \& O'kane, 1995), were expressed to impair synaptic transmission. This same approach has been followed by combining two binary systems. An enhancer-trap LexA was used to produce tissuespecific FLP via LexAop-FLP. In cells in which LexA and Gal4 expression overlap, the STOP sequence is excised from the $\mathrm{UAS}^{\mathrm{FRT}} \mathrm{STOP}^{\mathrm{FRT}}$ effector to permit Gal4-driven effector expression in restricted patterns (Yagi, Mayer, \& Basler, 2010).

\section{Effector lines to study neural circuits}

The Drosophila community generated a large collection of UAS-effectors (or other binary systems) to visualize cells, ablate cells, monitor neuronal and glial activity and manipulate neuronal function, and these effectors may be used to investigate the nervous system and behavior (Sivanantharajah \& Zhang, 2015). These effectors may be expressed in specific patterns using the intersectional methods explained in the previous section to gain access to a very detailed anatomical and functional map of the neural circuit that controls a behavior.

To visualize and anatomically study the neural circuits responsible for a behavior, there are a number of fluorescent protein markers and techniques that can be used to study the structure of neurons, map the connections between cells in the circuit and even trace their lineages during development. Cells in the nervous system are generally visualized using the Gal4-UAS system to express UAS-Reporter genes that encode fluorescent proteins. The most common protein is the GFP (Yeh, Gustafson, \& Boulianne, 1995) and the shift color derivatives red and yellow fluorescent proteins (RFP and YFP). Usually, these fluorescent proteins are targeted to mark different parts of cells of interest, such as the membrane (e.g. mCD8-GFP, a fusion protein between the transmembrane mouse lymphocyte marker CD8 and GFP) (Lee \& Luo, 1999), nucleus (e.g. nuclear localization signal (nls)GFP, where GFP is fused to a portion of the Tra protein of Drosophila, which is a nuclear localization signal) (Barolo, Carver, \& Posakony, 2000), specific organelles (e.g. mitoGFP for mitochondria, a chimeric gene encoding the N-terminal of human cytochrome $c$ oxidase subunit VIII (cCoxVIII) followed by GFP) (Pilling, Horiuchi, Lively, \& Saxton, 2006), axons (e.g. Tau-GFP, where the microtubule binding protein Tau is fused to GFP) (Ito, Sass, Urban, Hofbauer, \& Schneuwly, 1997), and dendrites (e.g. DenMark, a hybrid protein of the mouse protein ICAM5/telencephalin and the red fluorescent protein mCherry) (Nicolai et al., 2010). There are also UAS lines designed to label synapses to visualize the connections between the neurons of a circuit, and these markers may be presynaptic (e.g. nSyb-GFP, that marks the synaptic vesicles and the synaptic termini) (Estes et al., 2000), postsynaptic (e.g. Dlg-GFP, a fusion with Disc large, a postsynaptic density marker) (Koh, Popova, Thomas, Griffith, \& Budnik, 1999) or trans-synaptic labels (e.g. GRASP system, which expresses two transgenes encoding complementary parts of GFP in two populations of neurons, the GFP activity is reconstituted at synapses between the two populations) (Gordon \& Scott, 2009). Several recombinase- 
(A)

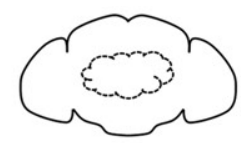
enhancer 1
expression

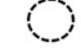

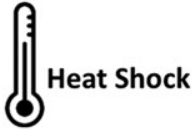

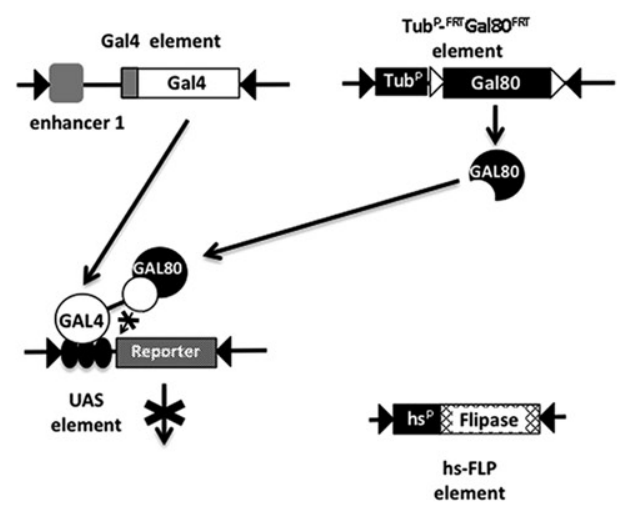

(B)
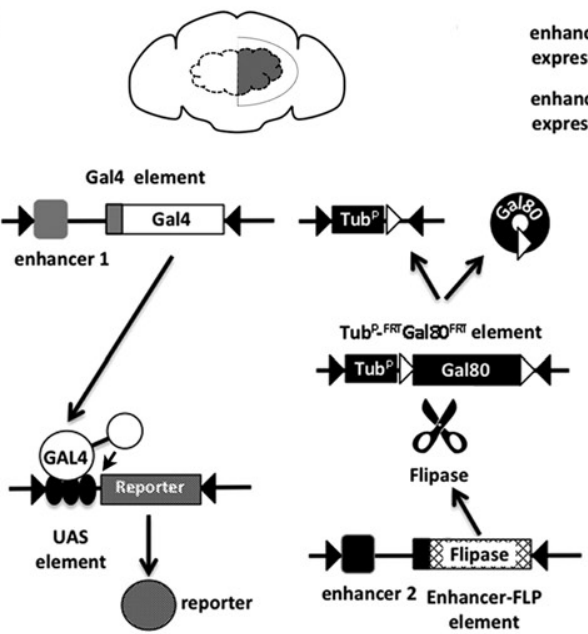
expression enhancer 2 expression
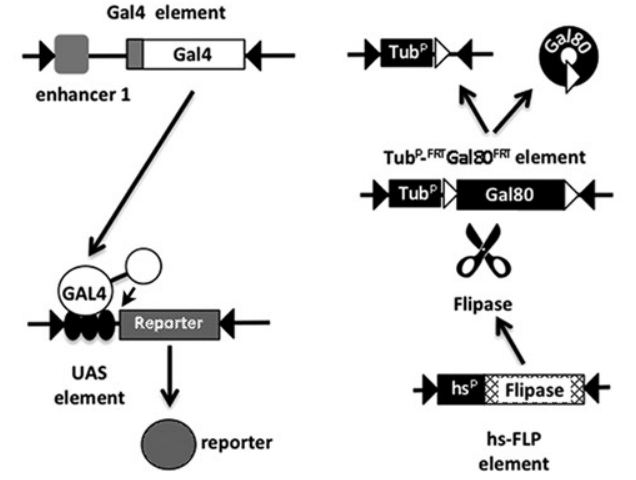

0

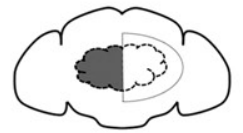

Gal4 element

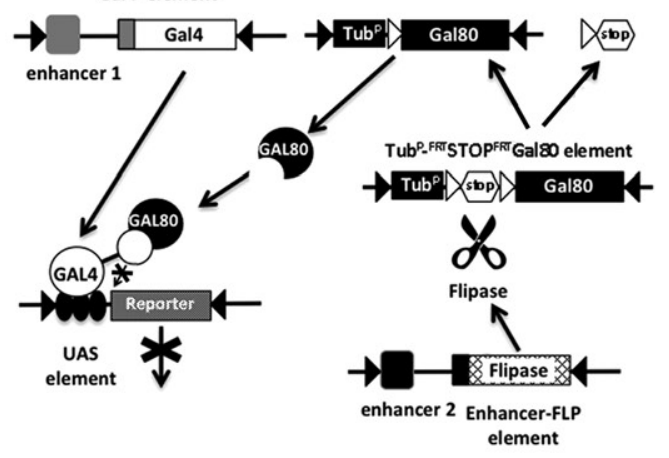

(C)

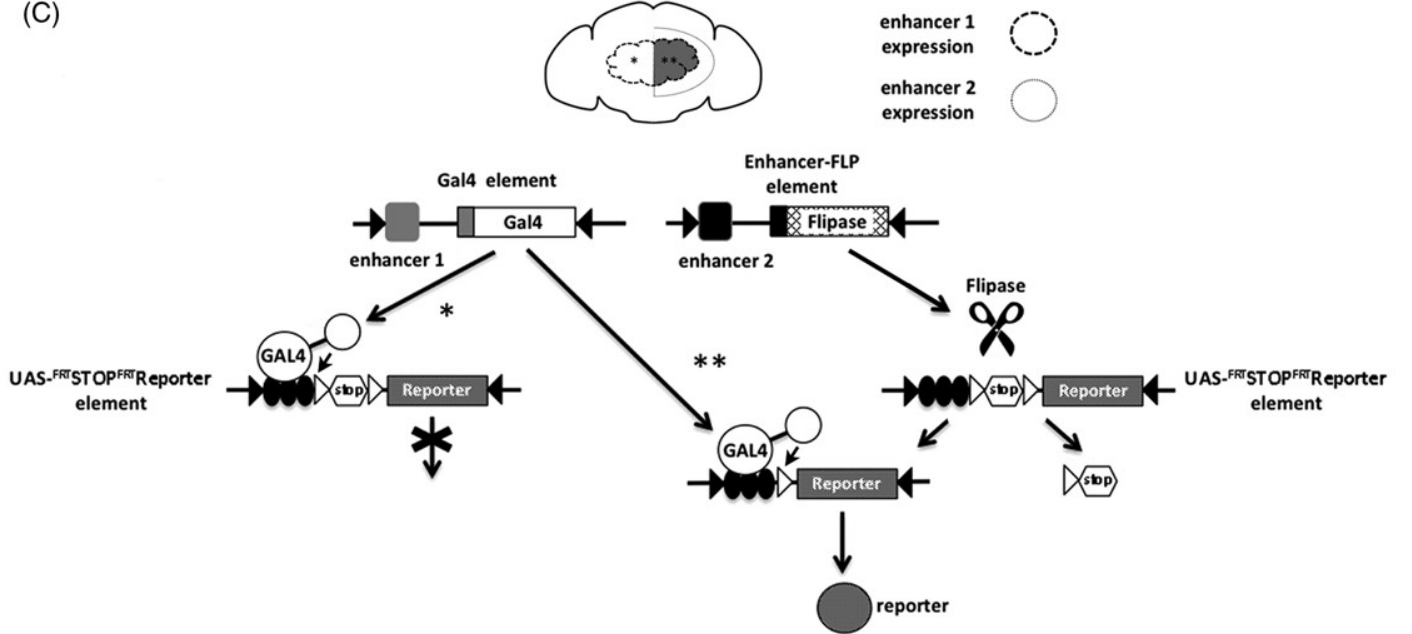

Figure 3. FLP/FRT based intersectional strategies. A) Gal80 flip-out: A Gal80 gene under the control of the Tubulin promoter (Tub ${ }^{\mathrm{P})}$ is inserted in between two FRT sites (white triangles). This Gal80 is going to repressed the expression of the reporter controlled by the Gal4/UAS system (left), but after a heat shock, the expression of a FLP gene under the control of a heat shock promoter (hs) is going to produce the flip out of the Gal80 gene as well as the expression of the reporter in the cells in which this occurs (right). The expression of the reporter is going to depend on the time during development when the heat shock was applied. B) The FINGR system, the FLP is controlled by an enhancer to refine the expression of the Gal4 driven by another enhancer. It could be induced by the flip out of the Gal80 gene where both enhancers intersect (left) or could be inhibited by the flip in of the Gal80 gene (because of the flip out of a Stop codon before the Gal80 gene) where both enhancers intersect (right). C) The UAS flip-in system, an enhancer driven FLP refines the expression of another enhancer-Gal4. The reporter is only expressed when both enhancers intersect $\left.{ }^{* *}\right)$ because the expression of the FLP produces the flip out of a stop codon between the UAS and the reporter. 
based cell labeling techniques are used to further refine the visualization of the neural circuits, such as the MARCM method explained above (Lee \& Luo, 2001), the flybow system (a derivative of the mouse brainbow system, that allow a multicolor cell labeling in neural circuits (Hadjieconomou et al., 2011)), or the coinFLP system (Bosch, Tran, \& Hariharan, 2015) that uses enhancer/promoter driven FLP constructs to produce mosaic individuals with restricted clonal expression of GAL4 and to visualize clonal boundaries. Real-time and lineage-traced expression patterns are also identifiable thanks to the Gal4-based system G-TRACE, which reports gene expression at a given developmental stage in combination with lineage information on expression at earlier developmental stages (Evans et al., 2009).

Effectors that kill the cells in which they are expressed are also used to investigate behavior. These effectors include pre-apoptotic genes, such as reaper (Zhou et al., 1997), or toxin subunits, such as the diphtheria toxin light chain (UAS-DTl) (Han et al., 2000).

Other useful effectors are those that are used to monitor the activity of the cells. They sense the rise in neuronal activity and produce an increase in their emitted fluorescence. These types of effectors include voltage sensitive GFPs, such as Arclight (Cao et al., 2013); pH sensitive fluorophores, such as pHluorin (Poskanzer, Marek, Sweeney, \& Davis, 2003); and $\mathrm{Ca}^{2+}$ sensors, such as GCaMP6 (Chen et al., 2013) or R-GECO (Dana et al., 2016). Some systems use molecular sensors that are irreversibly altered in the presence of elevated $\mathrm{Ca}^{2+}$ levels to identify neurons and neural circuits involved in a behavior response in fixed tissues. One of these systems is the CaLexA (calcium-dependent nuclear import of LexA), which uses a modified LexA fused to a transcription factor that is imported into the nucleus in an activity-dependent manner (the nuclear factor of activated $\mathrm{T}$ cells (NFAT)). Activated neurons are marked in this system because LexAop-GFP is expressed in their nuclei (Masuyama, Zhang, Rao, \& Wang, 2012). Another system uses the artificial protein calcium-modulated photoactivatable ratiometric integrator (CaMPARI), to identify activated neurons because it undergoes irreversible green-tored light emission conversion only when elevated intracellular $\mathrm{Ca}^{2+}$ and experimenter-controlled violet illumination coincide (Fosque et al., 2015).

The Gal4-UAS and the other binary systems may be used to investigate the neurons involved in a particular behavior, and also the required genes in these neurons. There are large collections of UAS-RNAi lines for the conditional inactivation of virtually any Drosophila gene thanks to the efforts of the Vienna Drosophila Resource Center (VDRC) (Dietzl et al., 2007) and the Transgenic RNAi Project (TRiP) (Ni et al., 2008). These UAS-RNAi lines express the interference RNA of a particular gene under the conditional control of a particular Gal4line and required the presence of an UAS-dcr2 construct for Dicer protein expression, which is necessary for the correct processing of RNAi. An in site-specific integration system derived from phage $\varphi \mathrm{C} 31$ is used in the TRIP RNAi lines to avoid position effects ( $\mathrm{Ni}$ et al., 2008).

\section{Manipulation of neural circuit function}

Manipulation of cellular or circuit activity is required to map the cells required for a particular behavior. Several effectors are capable of increasing or reducing synaptic activity (i.e. change the trafficking of the synaptic vesicles) and other effectors produce excitation or silencing of the neuronal activity (usually transmembrane ion channels that change the electric properties of the neuron). For example, UAS-Syx $^{3-39}$ encodes a single-point mutation in Syntaxin and specifically enhances synaptic vesicle fusion (Lagow et al., 2007). In contrast, UAS-TNT expresses the tetanus toxin (TNT) light chain that cleaves synaptobrevin and silences synaptic vesicle exocytosis (Sweeney et al., 1995). Expression of $\mathrm{K}^{+}$rectifier channels, such as UAS-Kir2.1 (Baines, Uhler, Thompson, Sweeney, \& Bate, 2001; Paradis, Sweeney, \& Davis, 2001), UAS-EKO (White et al., 2001) or UAS-dORK (Nitabach, Blau, \& Holmes, 2002), silences neuronal activity. In contrast, the UAS-NaChBac, which expresses a bacterial sodium channel and increases $\mathrm{Na}^{+}$conductance, which induces neuronal excitation (Nitabach et al., 2006).

Some of these effectors are activated with temporal control using several methods and can be classified based on optogenetic, thermogenetic, and pharmacogenetic techniques.

One example of pharmacogenetics was the use of the capsaicin-sensitive cation receptor/channel VR1 to activate neurons by simply feeding capsaicin to flies (Donlea, Thimgan, Suzuki, Gottschalk, \& Shaw, 2011; Kottler et al., 2013). However, pharmacogenetics lacks the advantage of optogenetic and thermogenetic techniques because the latter techniques allow for acute manipulation of neural activity in freely moving animals with precise temporal control.

The first thermogenetic experiments used the UAS-shi ${ }^{\text {ts }}$ transgene which expresses a temperature sensitive dynamin. Neurotransmission is transiently blocked by elevating the temperature of the flies above the restrictive $29^{\circ} \mathrm{C}$ (Kitamoto, 2001). Other thermogenetic techniques use members from the transient receptor potential (Trp) cation channel family and activate the neurons with cold, such as UAS-TrpM8 (Peabody et al., 2009), or heat, such as UAStrpA1 (Keene \& Masek, 2012; Marella, Mann, \& Scott, 2012; Rosenzweig et al., 2005).

The first experiment with light-triggered neural activation (optogenetics) in live behaving fruit flies used the rat ATPresponsive $\mathrm{P} 2 \mathrm{X} 2$ receptor expression in neurons. Then, neurons were selectively activated via the photo release of an injected caged ATP (Lima \& Miesenbock, 2005). The most widely used optogenetic tools currently are based on microbial opsins, the channelrhodopsins. These proteins are cation channels that required a critical cofactor, the all-trans-retinal, which is provided in the fly's diet. Exposure of channelrhodopsin-expressing flies to intense blue light activates these channels and subsequent depolarizes neurons (Schroll et al., 2006). However, the low channel conductance and poor penetration through the fly cuticle of the short wavelength light that is required to activate channelrhodopsin impeded its application in adult fly behavioral studies. The first study 
of learning in Drosophila that expressed a UAS-channelrhodopsin2 (chR2) used transparent larvae (Schroll et al., 2006). UAS-chR2 was also used to examine the consequences of peripheral sensory neuron activation in adult flies (Gordon \& Scott, 2009; Root et al., 2008; Suh et al., 2007), and it has been successfully used in physiological studies in which the brain is directly illuminated after part of the head cuticle is removed (Gaudry, Hong, Kain, de Bivort, \& Wilson, 2013; Gruntman \& Turner, 2013; Nagel, Hong, \& Wilson, 2015; Yaksi \& Wilson, 2010).

Channelrhodopsin variants that are much more useful for adult fly behavior analyses were recently created. For example, the ChR2-XXL variant is most suitable for low-light stimulation because of its high expression levels and long open-state (Dawydow et al., 2014). Activation has been shifted into the red spectrum in other variants, such as UAS-ReaChR or CsChrimson, which increased the light penetration through the fly cuticle. The use of these light wavelengths apparently does not interfere with normal fly vision. These variants were successfully used in studies of adult behavior (Inagaki et al., 2014; Joseph, Sun, Tam, \& Carlson, 2017; Klapoetke et al., 2014; Owald et al., 2015; Wu et al., 2016).

Another opsin coupled to $\mathrm{Cl}^{2+}$ conductance, halorhodopsin, produces cell activity inhibition, and it has been used in studies of behavior (Inada, Kohsaka, Takasu, Matsunaga, \& Nose, 2011).

\section{The use of genetic tools in the study of behavior: some examples in the olfactory receptor system}

Many of the genetic tools described in this review were used in the study of the olfactory system in Drosophila at the receptor level and odor-driven behaviors. For example, mutagenesis by a single P-element insertion in enhancer-trap lines successfully generated olfactory reception behavior mutants (Anholt, Lyman, \& Mackay, 1996). The use of Gal4 P-element insertion mutagenesis allows the generation of olfactory behavior mutants (Martin, Kim, Gomez-Diaz, Hovemann, \& Alcorta, 2006) and further manipulation of ORN via the UAS expression control of genes and effectors, such as the overexpression of genes involved in transduction pathways or the impairment of the synaptic transmission with the TNT effector (Gomez-Diaz, Martin, \& Alcorta, 2004, 2006).

The identification of two gene families that encodes the molecular odorant receptors, the OR family and its orco coreceptor (Clyne et al., 1999; Gao \& Chess, 1999; Vosshall, Amrein, Morozov, Rzhetsky, \& Axel, 1999) and the IR family (Benton Vannice, Gomez-Diaz, \& Vosshall, 2009), allowed the generation of Or-Gal4 and Ir-Gal4 constructs, which were used to investigate many aspects of the olfactory system of Drosophila at the receptor level. For example, these constructs were used to perform expression experiments by driving reporters, such as GFP under UAS control. This technique demonstrated that only one or a few receptors are expressed in one ORN (Vosshall et al., 2000), that there are 49 classes of ORNs in adults based on the receptor that the ORN expresses (Abuin et al., 2011; Benton et al., 2009;
Couto, Alenius, \& Dickson, 2005; Silbering et al., 2011), and that they are stereotypically innervate 22 sensilla subtypes (special hairs with porous walls that house between 1 and 4 neurons) (Benton et al., 2009; Couto et al., 2005; Ronderos \& Smith, 2009; Silbering et al., 2011). Every ORN that expresses a particular odorant receptor projects its axon to the same glomerulus in the antennal lobe in the brain (Couto et al., 2005; Silbering et al., 2011), which produced a complete projection map of 49 glomeruli in the antennal lobe.

The Gal4-UAS binary system was also used to investigate the odorant response electrophysiological profiles of receptors by their ectopic expression in an empty neuron (Hallem \& Carlson, 2006; Hallem et al., 2004) and to analyze the contribution of individual ORNs to odor coding and behavior in the larvae (Fishilevich et al., 2005).

These odorant receptors Gal4 lines were also used to express functional effectors. For example, optogenetics was used to describe an innate olfactory avoidance response to $\mathrm{CO}_{2}$ (Suh et al., 2007). Pharmacogenetics (UAS-VR1 with capsaicin) along with $\mathrm{Ca}^{2+}$ activity monitoring (UASGCaMP) were used to investigate the presynaptic control mechanism that fine tunes olfactory behavior (Root et al., 2008). Non-synaptic lateral inhibition between the neurons grouped together in a sensilla was also demonstrated using optogenetic activation (UAS-ChR2) and inhibition of synaptic transmission (UAS-TNT) in electrophysiological recordings and behavior assays ( $\mathrm{Su}$, Menuz, Reisert, \& Carlson, 2012). Optogenetics was used in Drosophila larvae olfactory receptor neurons to investigate how individual neurons affected behavior (Störtkuhl \& Fiala, 2011) and chemotaxis along odor gradients (Schulze et al., 2015).

\section{Concluding remarks}

In this review, we have given a general overview of the existing and new genetically encoded tools in Drosophila to investigate fly neurobiology. We described several strategies to map the cells required for Drosophila behaviors and the new effectors or approaches to manipulate neural circuits in living behaving animals. Some of these techniques were developed in flies, but they are also applicable to other genetic model organisms, such as zebrafish and mice. For example, the recombinase-based intersectional methods were developed in mouse (Madisen et al., 2015).

The fly neurobiology field has a very bright future because of the steady appearance of new resources for manipulating neuronal function, such as new effectors, the expansion of the collections of various intersectional tools, such as split-Gal4, or the possible combination of genetic on and off switches together with neuronal activity recording methods and behavioral analyses. The development of tethered fly preparations permit neural manipulation and recording during animal behavior (Maimon, Straw, \& Dickinson, 2010; Seelig et al., 2010). For example, one preparation used a pharyngeal pumping assay and the expression of effectors that inhibits (UAS-TNT) or activates (UASCsChrimson) neurons to identify one gustatory neuron that limited sucrose consumption and the molecular receptor 
required for this behavior (Ir60b) (Joseph et al., 2017). The fly brain uses similar neurotransmitters, channels, and wiring modules as mammalian brains. Therefore, this research will continue to be useful to improve our understanding of the principles and mechanisms of the basic brain functions associated with behaviors.

\section{Disclosure statement}

No potential conflict of interest was reported by the authors.

\section{Funding}

This work was supported by the Spanish Ministry of Economy and Competitiveness (SAF2013-48759-P), the Principado de Asturias (GRUPIN14-012), and FEDER Funds.

\section{ORCID}

Fernando Martín (D) http://orcid.org/0000-0003-4380-567X

\section{References}

Abuin, L., Bargeton, B., Ulbrich, M.H., Isacoff, E.Y., Kellenberger, S., \& Benton, R. (2011). Functional architecture of olfactory ionotropic glutamate receptors. Neuron, 69, 44-60. doi: 10.1016/j.neuron.2010. 11.042 .

Anholt, R.R.H., Lyman, R.F., \& Mackay, T.F.C. (1996). Effects of single P-element insertions on olfactory behavior in Drosophila melanogaster. Genetics, 143, 293-301.

Baines, R.A., Uhler, J.P., Thompson, A., Sweeney, S.T., \& Bate, M. (2001). Altered electrical properties in Drosophila neurons developing without synaptic transmission. Journal of Neuroscience, 21, $1523-1531$.

Bargmann, C.I., \& Marder, E. (2013). From the connectome to brain function. Nature Methods, 10, 483-490. doi: 10.1038/nmeth.2451.

Barolo, S., Carver, L.A., \& Posakony, J.W. (2000). GFP and beta-galactosidase transformation vectors for promoter/enhancer analysis in Drosophila. BioTechniques, 29, 726-732.

Bellen, H.J., O'kane, C.J., Wilson, C., Grossniklaus, U., Pearson, R.K., \& Gehring, W.J. (1989). P-element-mediated enhancer detection: A versatile method to study development in Drosophila. Gene \& Development, 3, 1288-1300. doi: 10.1101/gad.3.9.1288.

Benton, R., Vannice, K.S., Gomez-Diaz, C., \& Vosshall, L.B. (2009). Variant ionotropic glutamate receptors as chemosensory receptors in Drosophila. Cell, 136, 149-162. doi: 10.1016/j.cell.2008.12.001.

Benzer, S. (1973). Genetic dissection of behavior. Scientific American, 229, 24-37. doi: 10.1038/scientificamerican1273-24.

Behnia, R., \& Desplan, C. (2015). Visual circuits in flies: Beginning to see the whole picture. Current Opinion Neurobiology, 34, 125-132. doi: 10.1016/j.conb.2015.03.010.

Bosch, J.A., Tran, N.H., \& Hariharan, I.K. (2015). CoinFLP: A system for efficient mosaic screening and for visualizing clonal boundaries in Drosophila. Development (Cambridge, England), 142, 597-606. doi: $10.1242 /$ dev.114603.

Brand, A.H., \& Perrimon, N. (1993). Targeted gene expression as a means of altering cell fates and generating dominant phenotypes. Development, 118, 401-415.

Cao, G., Platisa, J., Pieribone, V.A., Raccuglia, D., Kunst, M., \& Nitabach, M.N. (2013). Genetically targeted optical electrophysiology in intact neural circuits. Cell, 154, 904-913. doi: 10.1016/j.cell.2013. 07.027.

Chen, T.W., Wardill, T.J., Sun, Y., Pulver, S.R., Renninger, S.L., Baohan, A., ... Kim, D.S. (2013). Ultrasensitive fluorescent proteins for imaging neuronal activity. Nature, 499, 295-300. doi: 10.1038/ nature12354.

Clyne, J.D., \& Miesenbock, G. (2008). Sex-specific control and tuning of the pattern generator for courtship song in Drosophila. Cell, 133, 354-363. doi: 10.1016/j.cell.2008.01.050.

Clyne, P.J., Warr, C.G., Freeman, M.R., Lessing, D., Kim, J., \& Carlson, J.R. (1999). A novel family of divergent seven-transmembrane proteins: Candidate odorant receptors in Drosophila. Neuron, 22, 327-338. doi: 10.1016/S0896-6273(00)81093-4

Couto, A., Alenius, M., \& Dickson, B.J. (2005). Molecular, anatomical and functional organization of the Drosophila olfactory system. Current Biology, 15, 1535-1547. doi: 10.1016/j.cub.2005.07.034.

Dana, H., Mohar, B., Sun, Y., Narayan, S., Gordus, A., Hasseman, J.P., ... Kim, D.S. (2016). Sensitive red protein calcium indicators for imaging neural activity. Elife, 5, e12727. doi: 10.7554/eLife.12727.

Dawydow, A., Gueta, R., Ljaschenko, D., Ullrich, S., Hermann, M., Ehmanna, N., ... Kittel, R.J. (2014). Channelrhodopsin-2-XXL, a powerful optogenetic tool for low-light applications. Proceedings of the National Academy of Sciences of United States of America, 111, 13972-13977. doi: 10.1073/pnas.1408269111.

Donlea, J.M., Thimgan, M.S., Suzuki, Y., Gottschalk, L., \& Shaw, P.J. (2011). Inducing sleep by remote control facilitates memory consolidation in Drosophila. Science, 332, 1571-1576. doi: 10.1126/science. 1202249.

Eichler, K., Li, F., Litwin-Kumar, A., Park, Y., Andrade, I., SchneiderMizell, C.M., ... Cardona, A. (2017). The complete connectome of a learning and memory centre in an insect brain. Nature, 548, 175-182. doi: 10.1038/nature23455.

Evans, C.J., Olson, J.M., Ngo, K.T., Kim, E., Lee, N.E., Kuoy, E., ... Banerjee, U. (2009). G-TRACE: rapid Gal4-based cell lineage analysis in Drosophila. Nature Methods, 6, 603-605. doi: 10.1038/nmeth. 1356.

Fishilevich, E., Domingos, A.I., Asahina, K., Naef, F., Vosshall, L.B., \& Louis, M. (2005). Chemotaxis behavior mediated by single larval olfactory neurons in Drosophila. Current Biology, 15, 2086-2096. doi: 10.1016/j.cub.2005.11.016.

Fosque, B.F., Sun, Y., Dana, H., Yang, C.T., Ohyama, T., Tadross, M.R., ... Schreiter, E.R. (2015). Neural circuits. Labeling of active neural circuits in vivo with designed calcium integrators. Science, 347, 755-760. doi: 10.1126/science.1260922.

Gao, Q., \& Chess, A. (1999). Identification of candidate Drosophila olfactory receptors from genomic DNA sequence. Genomics, 60, 31-39. doi: 10.1006/geno.1999.5894.

Gaudry, Q., Hong, E.J., Kain, J., de Bivort, B.L., \& Wilson, R.I. (2013). Asymmetric neurotransmitter release enables rapid odour lateralization in Drosophila. Nature, 493, 424-428. doi: 10.1038/nature11747.

Gomez-Diaz, C., Martin, F., \& Alcorta, E. (2004). The cAMP transduction cascade mediates olfactory reception in Drosophila melanogaster Behavior Genetics, 34, 395-406. doi: 10.1023/B:BEGE.0000023645. 02710.fe.

Gomez-Diaz, C., Martin, F., \& Alcorta, E. (2006). The Inositol 1,4,5-triphosphate kinase1 gene affects olfactory reception in Drosophila melanogaster. Behavior Genetics, 36, 309-321. doi: 10.1007/s10519-0059031-x.

Gordon, M.D., \& Scott, K. (2009). Motor control in a Drosophila taste circuit. Neuron, 61, 373-384. doi: 10.1016/j.neuron.2008.12.033.

Golic, K.G., \& Lindquist, S. (1989). The FLP recombinase of yeast catalyzes site-specific recombination in the Drosophila genome. Cell, 59, 499-509. 10.1016/0092-8674(89)90033-0

Groth, A.C., Fish, M., Nusse, R., \& Calos, M.P. (2004). Construction of transgenic Drosophila by using the site-specific integrase from phage phiC31. Genetics, 166, 1775-1782. doi: 10.1534/genetics.166.4.1775.

Gruntman, E., \& Turner, G.C. (2013). Integration of the olfactory code across dendritic claws of single mushroom body neurons. Nature Neuroscience, 16, 1821-1829. doi: 10.1038/nn.3547.

Hadjieconomou, D., Rotkopf, S., Alexandre, C., Bell, D.M., Dickson, B.J., \& Salecker, I. (2011). Flybow: Genetic multicolor cell labeling for neural circuit analysis in Drosophila melanogaster. Nature Methods, 8, 260-266. doi: 10.1038/nmeth.1567. 
Herrero, P. (2012). Fruit fly behavior in response to chemosensory signals. Peptides, 38, 228-237. doi: 10.1016/j.peptides.2012.09.019.

Iliadi, K.G. (2009). The genetic basis of emotional behavior: has the time come for a Drosophila model. Journal of Neurogenetics, 23, 136-146. doi: 10.1080/01677060802471650.

Inada, K., Kohsaka, H., Takasu, E., Matsunaga, T., \& Nose, A. (2011). Optical dissection of neural circuits responsible for Drosophila larval locomotion with halorhodopsin. PLoS One, 6, e29019. doi: 10.1371/ journal.pone.0029019.

Inagaki, H.K., Jung, Y., Hoopfer, E.D., Wong, A.M., Mishra, N., Lin, J.Y., ... Anderson, D.J. (2014). Optogenetic control of Drosophila using a red-shifted channelrhodopsin reveals experience-dependent influences on courtship. Nature Methods, 11, 325-332. doi: 10.1038/ nmeth.2765.

Ito, K., Sass, H., Urban, J., Hofbauer, A., \& Schneuwly, S. (1997). GAL4-responsive UAS-tau as a tool for studying the anatomy and development of the Drosophila central nervous system. Cell and Tissue Research, 290, 1-10. doi: 10.1007/s004410050901.

Ito, M., Masuda, N., Shinomiya, K., Endo, K., \& Ito, K. (2013). Systematic analysis of neural projections reveals clonal composition of the Drosophila brain. Current Biology, 23, 644-655. doi: 10.1016/ j.cub.2013.03.015.

Joseph, M.R., Sun, J.S., Tam, E., \& Carlson, J.R. (2017). A receptor and neuron that activate a circuit limiting sucrose consumption. Elife, 6, e24992. doi: 10.7554/eLife.24992.

Johnston, M. (1987). A model fungal gene regulatory mechanism: The GAL genes of Saccharomyces cerevisiae. Microbiological Reviews, 51, 458-476.

Kamikouchi, A. (2013). Auditory neuroscience in fruit flies. Neuroscience Research, 76, 113-118. doi: 10.1016/j.neures.2013.04. 003.

Keene, A.C., Stratmann, M., Keller, A., Perrat, P.N., Vosshall, L.B., \& Waddell, S. (2004). Diverse odor-conditioned memories require uniquely timed dorsal paired medial neuron output. Neuron, 44, 521-533. doi: 10.1016/j.neuron.2004.10.006.

Kitamoto, T. (2001). Conditional modification of behavior in Drosophila by targeted expression of a temperature-sensitive shibire allele in defined neurons. Journal of Neurobiology, 47, 81-92. doi: $10.1002 /$ neu. 1018

Klapoetke, N.C., Murata, Y., Kim, S.S., Pulver, S.R., Birdsey-Benson, A., Cho, Y.K., ... Boyden, E.S. (2014). Independent optical excitation of distinct neural populations. Nature Methods, 11, 338-346. doi: 10. 1038/nmeth.2836.

Koh, Y.H., Popova, E., Thomas, U., Griffith, L.C., \& Budnik, V. (1999). Regulation of DLG localization at synapses by CaMKII-dependent phosphorylation. Cell, 98, 353-363. doi: 10.1016/S00928674(00)81964-9.

Kottler, B., Bao, H., Zalucki, O., Imlach, W., Troup, M., van Alphen, B., ... van Swinderen, B. (2013). A sleep/wake circuit controls isoflurane sensitivity in Drosophila. Current Biology, 23, 594-598. doi: 10.1016/j.cub.2013.02.021.

Lagow, R.D., Bao, H., Cohen, E.N., Daniels, R.W., Zuzek, A., Williams, W.H., ... Zhang, B. (2007). Modification of a hydrophobic layer by a point mutation in syntaxin $1 \mathrm{~A}$ regulates the rate of synaptic vesicle fusion. PLoS Biology, 5, e72. doi: 10.1371/journal.pbio.0050072.

Lai, S.L., \& Lee, T. (2006). Genetic mosaic with dual binary transcriptional systems in Drosophila. Nature Neuroscience, 9, 703-709. doi: doi: $10.1038 / \mathrm{nn} 1681$.

Lee, T., \& Luo, L. (1999). Mosaic analysis with a repressible cell marker for studies of gene function in neuronal morphogenesis. Neuron, 22, 451-461. doi: 10.1016/S0896-6273(00)80701-1.

Lee, T., \& Luo, L. (2001). Mosaic analysis with a repressible cell marker (MARCM) for Drosophila neural development. Trends in Neurosciences, 24, 251-254. doi: 10.1016/S0166-2236(00)01791-4.

Levis, R., Hazelrigg, T., \& Rubin, G.M. (1985). Effects of genomic position on the expression of transduced copies of the white gene of Drosophila. Science, 229, 558-561. doi: 10.1126/science.2992080.

Lima, S.Q., \& Miesenbock, G. (2005). Remote control of behavior through genetically targeted photostimulation of neurons. Cell, 121, 141-152. doi: 10.1016/j.cell.2005.02.004.
Lumpkin, E.A., Marshall, K.L., \& Nelson, A.M. (2010). The cell biology of touch. Journal of Cell Biology, 191, 237-248. doi: 10.1083/jcb. 201006074.

Madisen, L., Garner, A.R., Shimaoka, D., Chuong, A.S., Klapoetke, N.C., Li, L., ... Zeng, H. (2015). Transgenic mice for intersectional targeting of neural sensors and effectors with high specificity and performance. Neuron, 85, 942-958. doi: 10.1016/j.neuron.2015.02. 022.

Maimon, G., Straw, A.D., \& Dickinson, M.H. (2010). Active flight increases the gain of visual motion processing in Drosophila. Nature Neuroscience, 13, 393-399. doi: 10.1038/nn.2492.

Marella, S., Mann, K., \& Scott, K. (2012). Dopaminergic modulation of sucrose acceptance behavior in Drosophila. Neuron, 73, 941-950. doi: 10.1016/j.neuron.2011.12.032.

Martin, F., Boto, T., Gomez-Diaz, C., \& Alcorta, E. (2013). Elements of olfactory reception in adult Drosophila melanogaster. Anatomical Record (Hoboken), 296, 1477-1488. doi: 10.1002/ar.22747.

Martin, F., Kim, M.S., Gomez-Diaz, C., Hovemann, B., \& Alcorta, E. (2006). High efficiency of a double-screening method on single P-element insertion lines to identify quantitative trait mutants in Drosophila melanogaster. Genetica, 128, 359-372. doi: 10.1007/ s10709-006-7354-z.

Masuyama, K., Zhang, Y., Rao, Y., \& Wang, J.W. (2012). Mapping Neural Circuits with Activity-Dependent Nuclear Import of a Transcription Factor. Journal of Neurogenetics, 26, 89-102. doi: 10. 3109/01677063.2011.642910.

McGuire, S.E., Le, P.T., Osborn, A.J., Matsumoto, K., \& Davis, R.L. (2003). Spatiotemporal rescue of memory dysfunction in Drosophila. Science, 302, 1765-1768. doi: 10.1126/science.1089035.

McGurk, L., Berson, A., \& Bonini, N.M. (2015). Drosophila as an In Vivo Model for Human Neurodegenerative Disease. Genetics, 201, 377-402. doi: 10.1534/genetics.115.179457.

Nagel, K.I., Hong, E.J., \& Wilson, R.I. (2015). Synaptic and circuit mechanisms promoting broadband transmission of olfactory stimulus dynamics. Nature Neuroscience, 18, 56-65. doi: 10.1038/nn.3895.

Ng, M., Roorda, R.D., Lima, S.Q., Zemelman, B.V., Morcillo, P., \& Miesenbock, G. (2002). Transmission of olfactory information between three populations of neurons in the antennal lobe of the fly. Neuron, 36, 463-474. doi: 10.1016/S0896-6273(02)00975-3.

Ni, J.Q., Markstein, M., Binari, R., Pfeiffer, B., Liu, L.P., Villalta, C., ... Perrimon, N. (2008). Vector and parameters for targeted transgenic RNA interference in Drosophila melanogaster. Nature Methods, 5 , 49-51. doi: 10.1038/nmeth1146.

Nicolai, L.J., Ramaekers, A., Raemaekers, T., Drozdzecki, A., Mauss, A.S., Yan, J., ... Hassan, B.A. (2010). Genetically encoded dendritic marker sheds light on neuronal connectivity in Drosophila. Proceedings of the National Academy of Sciences, 107, 20553-20558. doi: 10.1073/pnas.1010198107.

Nitabach, M.N., Blau, J., \& Holmes, T.C. (2002). Electrical silencing of Drosophila pacemaker neurons stops the free-running circadian clock. Cell, 109, 485-495. 10.1016/S0092-8674(02)00737-7

Nitabach, M.N., Wu, Y., Sheeba, V., Lemon, W.C., Strumbos, J., Zelensky, P.K., ... Holmes, T.C. (2006). Electrical hyperexcitation of lateral ventral pacemaker neurons desynchronizes downstream circadian oscillators in the fly circadian circuit and induces multiple behavioral periods. Journal of Neuroscience, 26, 479-489. doi: 10. 1523/JNEUROSCI.3915-05.2006.

O'Kane, C.J., \& Gehring, W.J. (1987). Detection in situ of genomic regulatory elements in Drosophila. Proceedings of the National Academy of Sciences, 84, 9123-9127.

Osterwalder, T., Yoon, K.S., White, B.H., \$., \& Keshishian, H. (2001). A conditional tissue-specific transgene expression system using inducible GAL4. Proceedings of the National Academy of Sciences, 98, 12596-12601. doi: 10.1073/pnas.221303298.

Owald, D., Felsenberg, J., Talbot, C.B., Das, G., Perisse, E., Huetteroth, W., \& Waddell, S. (2015). Activity of defined mushroom body output neurons underlies learned olfactory behavior in Drosophila. Neuron, 86, 417-427. doi: 10.1016/j.neuron.2015.03.025.

Paradis, S., Sweeney, S.T., \& Davis, G.W. (2001). Homeostatic control of presynaptic release is triggered by postsynaptic membrane 
depolarization. Neuron, 30, 737-749. doi: 10.1016/S08966273(01)00326-9.

Park, A., Ghezzi, A., Wijesekera, T.P., \& Atkinson, N.S. (2017) Genetics and genomics of alcohol responses in Drosophila. Neuropharmacology, 122, 22-35. doi: 10.1016/j.neuropharm.2017.01. 032.

Peabody, N.C., Pohl, J.B., Diao, F., Vreede, A.P., Sandstrom, D.J... \& Wang, H. (2009). Characterization of the decision network for wing expansion in Drosophila using targeted expression of the TRPM8 channel. Journal of Neuroscience, 29, 3343-3353. doi: 10.1523/ JNEUROSCI.4241-08.2009.

Pilling, A.D., Horiuchi, D., Lively, C.M., \& Saxton, W.M. (2006). Kinesin-1 and Dynein are the primary motors for fast transport of mitochondria in Drosophila motor axons. Molecular Biology of the Cell, 17, 2057-2068. doi: 10.1091/mbc.E05-06-0526.

Poskanzer, K.E., Marek, K.W., Sweeney, S.T., \& Davis, G.W. (2003) Synaptotagmin I is necessary for compensatory synaptic vesicle endocytosis in vivo. Nature, 426, 559-563. doi: 10.1038/ nature 02184 .

Potter, C.J., \& Luo, L. (2011). Using the Q system in Drosophila melanogaster. Nature Protocols, 6, 1105-1120. doi: 10.1038/nprot.2011. 347.

Potter, C.J., Tasic, B., Russler, E.V., Liang, L., \& Luo, L. (2010). The Q system: a repressible binary system for transgene expression, lineage tracing, and mosaic analysis. Cell, 141, 536-548. doi: 10.1016/j.cell. 2010.02.025.

Ramdya, P., Schneider, J., \& Levine, J.D. (2017). The neurogenetics of group behavior in Drosophila melanogaster. Journal of Experimental Biology, 220, 35-41. doi: 10.1242/jeb.141457.

Rodríguez, A., del, V., Didiano, D., \& Desplan, C. (2011). Power tools for gene expression and clonal analysis in Drosophila. Nature Methods, 9, 47-55. doi: 10.1038/nmeth.1800.

Roman, G., Endo, K., Zong, L., \& Davis, R.L. (2001). P[Switch], a system for spatial and temporal control of gene expression in Drosophila melanogaster. Proceedings of Natural Academy of Science of United States of America, 98, 12602-12607. doi: 10.1073/pnas. 221303998.

Ronderos, D.S., \& Smith, D.P. (2009). Diverse signaling mechanisms mediate volatile odorant detection in Drosophila. Fly (Austin), 3, 290-297. doi: 10.4161/fly.9801.

Root, C.M., Masuyama, K., Green, D.S., Enell, L.E., Nässel, D.R., Lee, C.-H., \& Wang, J.W. (2008). A presynaptic gain control mechanism fine-tunes olfactory behavior. Neuron, 59, 311-321. doi: 10.1016/j. neuron.2008.07.003.

Rosenzweig, M., Brennan, K.M., Tayler, T.D., Phelps, P.O., Patapoutian, A., \& Garrity, P.A. (2005). The Drosophila ortholog of vertebrate TRPA1 regulates thermotaxis. Genes and Development, 19, 419-424. doi: 10.1101/gad.1278205.

Rubin, G.M., \& Spradling, A.C. (1982). Genetic transformation of Drosophila with transposable element vectors. Science, 218, 348-353. doi: 10.1126/science.6289436.

Rubin, G.M., Yandell, M.D., Wortman, J.R., Gabor Miklos, G.L., Nelson, C.R., Hariharan, I.K., ... Lewis, S. (2000). Comparative genomics of the eukaryotes. Science, 287, 2204-2215.

Ryder, E., \& Russell, S. (2003). Transposable elements as tools for genomics and genetics in Drosophila. Briefings in Functional Genomics \& Proteomics, 2, 57-71. doi: 10.1093/bfgp/2.1.57.

Schroll, C., Riemensperger, T., Bucher, D., Ehmer, J., Völler, T., Erbguth, K., ... Fiala, A. (2006). Light-induced activation of distinct modulatory neurons triggers appetitive or aversive learning in Drosophila larvae. Current Biology, 16, 1741-1747. doi: 10.1016/j. cub.2006.07.023.

Seelig, J.D., Chiappe, M.E., Lott, G.K., Dutta, A., Osborne, J.E., Reiser, M.B., \& Jayaraman, V. (2010). Two-photon calcium imaging from head-fixed Drosophila during optomotor walking behavior. Nature Methods, 7, 535-540. doi: 10.1038/nmeth.1468.

Silbering, A.F., Rytz, R., Grosjean, Y., Abuin, L., Ramdya, P., Jefferis, G.S., \& Benton, R. (2011). Complementary function and integrated wiring of the evolutionarily distinct Drosophila olfactory subsystems.
Journal of Neuroscience, 31, 13357-13375. doi: 10.1523/JNEUROSCI. 2360-11.2011.

Simpson, J.H. (2009). Mapping and manipulating neural circuits in the fly brain. Advances in Genetics, 65, 79-143. doi: 10.1016/S00652660(09)65003-3.

Sivanantharajah, L., \& Zhang, B. (2015). Current techniques for highresolution mapping of behavioral circuits in Drosophila. Journal of comparative physiology. A, Neuroethology, sensory, neural, and behavioral physiology, 201, 895-909. doi: 10.1007/s00359-015-1010-y.

Sokolowski, M.B. (2001). Drosophila: genetics meets behaviour. Nature Reviews Genetics, 2, 879-890. doi: 10.1038/35098592.

Spradling, A.C., \& Rubin, G.M. (1982). Transposition of cloned P elements into Drosophila germ line chromosomes. Science, 218, 341-347. 10.1126/science.6289435

Stockinger, P., Kvitsiani, D., Rotkopf, S., Tirian, L., \& Dickson, B.J. (2005). Neural circuitry that governs Drosophila male courtship behavior. Cell, 121, 795-807. doi: 10.1016/j.cell.2005.04.026.

Störtkuhl, K.F., \& Fiala, A. (2011). The smell of blue light: a new approach toward understanding an olfactory neuronal network. Frontiers in Neuroscience, 5, 72. doi: 10.3389/fnins.2011.00072.

Su, C.Y., Menuz, K., Reisert, J., \& Carlson, J.R. (2012). Non-synaptic inhibition between grouped neurons in an olfactory circuit. Nature, 492, 66-71. doi: 10.1038/nature11712.

Suh, G.S., Ben-Tabou de Leon, S., Tanimoto, H., Fiala, A., Benzer, S., \& Anderson, D.J. (2007). Light activation of an innate olfactory avoidance response in Drosophila. Current Biology, 17, 905-908. doi: 10. 1016/j.cub.2007.04.046

Sweeney, S.T., Broadie, K., Keane, J., Niemann, H., \& O'kane, C.J (1995). Targeted expression of tetanus toxin light chain in Drosophila specifically eliminates synaptic transmission and causes behavioral defects. Neuron, 14, 341-351. doi: 10.1016/08966273(95)90290-2.

Schulze, A., Gomez-Marin, A., Rajendran, V.G., Lott, G., Musy, M. Ahammad, P., ... Louis, M. (2015). Dynamical feature extraction at the sensory periphery guides chemotaxis. The Journal eLife, 4, e06694. doi: 10.7554/eLife.06694.

Takemura, S., Xu, S., Lu, Z., Rivlin, P.K., Parag, T., Olbris, D.J., ... Scheffer, L.K. (2015). Synaptic circuits and their variations within different columns in the visual system of Drosophila. Proceedings of the National Academy of Sciences, 112, 13711-13716. doi: 10.1073/ pnas. 1509820112 .

Ting, C.Y., Gu, S., Guttikonda, S., Lin, T.Y., White, B.H., \& Lee, C.H. (2011). Focusing transgene expression in Drosophila by coupling Gal4 with a novel split-LexA expression system. Genetics, 188, 229-233. doi: 10.1534/genetics.110.126193.

Vosshall, L.B., Amrein, H., Morozov, P.S., Rzhetsky, A., \& Axel, R. (1999). A spatial map of olfactory receptor expression in the Drosophila antenna. Cell, 96, 725-736. doi: 10.1016/S00928674(00)80582-6.

Vosshall, L.B., \& Stocker, R.F. (2007). Molecular architecture of smell and taste in Drosophila. Annual Review of Neuroscience, 30, 505-533. doi: 10.1146/annurev.neuro.30.051606.094306.

White, B.H., Osterwalder, T.P., Yoon, K.S., Joiner, W.J., Whim, M.D. Kaczmarek, L.K., \& Keshishian, H. (2001). Targeted attenuation of electrical activity in Drosophila using a genetically modified K(+)channel. Neuron, 31, 699-711. doi: 10.1016/S08966273(01)00415-9.

White, B.H., \& Peabody, N.C. (2009). Neurotrapping: cellular screens to identify the neural substrates of behavior in Drosophila. Frontiers in Molecular Neuroscience, 2, 20. doi: 10.3389/neuro.02.020. 2009.

Wu, M., Nern, A., Williamson, W.R., Morimoto, M.M., Reiser, M.B., Card, G.M., \& Rubin, G.M. (2016). Visual projection neurons in the Drosophila lobula link feature detection to distinct behavioral programs. The Journal eLife, 5, e21022. doi: 10.7554/eLife.21022.

Yagi, R., Mayer, F., \& Basler, K. (2010). Refined LexA transactivators and their use in combination with the Drosophila Gal4 system. Proceedings of the National Academy of Sciences of United States of America, 107, 16166-16171. doi: 10.1073/pnas.1005957107. 
Yaksi, E., \& Wilson, R.I. (2010). Electrical coupling between olfactory glomeruli. Neuron, 67, 1034-1047. doi: 10.1016/j.neuron.2010.08.041.

Yeh, E., Gustafson, K., \& Boulianne, G.L. (1995). Green fluorescent protein as a vital marker and reporter of gene expression in Drosophila. Proceedings of the National Academy of Sciences, 92, 7036-7040. doi: 10.1073/pnas.92.15.7036.

Zelensky, P.K., \& White, B.H. (2009). Characterization of the decision network for wing expansion in Drosophila using targeted expression of the TRPM8 channel. Journal of Neuroscience, 29, 3343-3353. doi: 10.1523/JNEUROSCI.4241-08.2009.

Zhou, L., Schnitzler, A., Agapite, J., Schwartz, L.M., Steller, H., \& Nambu, J.R. (1997). Cooperative functions of the reaper and head involution defective genes in the programmed cell death of Drosophila central nervous system midline cells. Proceedings of the National Academy of Sciences, 94, 5131-5136. doi: 10.1073/pnas.94. 10.5131 